Paideusis

\title{
Languages of Educational Discourse: Process, Procedure and Skill
}

\section{Charles Bailey}

Volume 4, Number 2, 1991

URI: https://id.erudit.org/iderudit/1073379ar

DOI: https://doi.org/10.7202/1073379ar

See table of contents

Publisher(s)

Canadian Philosophy of Education Society

ISSN

0838-4517 (print)

1916-0348 (digital)

Explore this journal

Cite this article

Bailey, C. (1991). Languages of Educational Discourse: Process, Procedure and Skill. Paideusis, 4(2), 3-15. https://doi.org/10.7202/1073379ar viewed online.

https://apropos.erudit.org/en/users/policy-on-use/ 


\section{Languages of Educational Discourse: Process, Procedure and Skill}

\section{Charles Bailey, Homerton College, Cambridge}

If the way in which educational debate has gone on in England in the last few decades is anything to go by, it is clear that such debate does not take place in a unified discourse in which all participants use the same language, or even the same rules of debate. The very exercise of some people trying to convince others that certain things should happen in education, and that certain other things should not, of course, presupposes that such a common language and such common ground-rules of truth-testing, or at least refutation, do exist and are the stock-in-trade of all who join in the arguments. It only makes sense for one to assert that such and such is the case, or that this ought to happen and that not, on the assumption that others can in some common way test the claims. But this general claim by philosophers and some others about the logical status and presuppositions of argument, while descriptive, is only descriptive in a limited way. That is to say, the claim describes what ought to count as a proper argument; it does not describe how people and agencies of one kind or another actually conduct what they are happy to call 'argument' or 'debate'. Whilst this can be extremely frustrating to the philosophically-minded educator, it has to be accepted that what is factual description for one can seem like simple prescription, which need not be heeded, by another. What is even more galling to those in the community of philosophically-minded educators -- I speak at least for myself but I am sure for many more -- is that in the world of decision-making the 'proper argument' does not always win the day.

There are a number of reasons for this and it is not the purpose of this paper to examine all of these. It might help, however, and it might encourage others to dig deeper were I to make some preliminary distinctions. For a start, I am not really talking here about the common and important distinction between power and reason. This is, of course, the long-standing difference between sociologists of education who claim to show in a more-or-less deterministic way what actually shapes educational policy and practice and philosophers of education who with some oversimplification might be described as concerning themselves with what ought to be the shape of educational policy and practice. Sociologists are right to claim that at least sometimes what influences educational practice is power rather than argument. This has certainly been the case in recent years in England and Wales where a determined government has imposed a number of profound changes on the educational system in the face of much opposing argument. The presence of a large majority of government supporters in the House of Commons has been far more important in these events than anything written by any philosopher of education. This, while true, is to make the distinction appear somewhat too clear-cut. For another element is what might be called chronological delay. What happens is that, although at any given time, power seems to conflict with argument, and a gulf exists between political power and theoretical debate, the direction of present power is often derived from theoretical writing of some time past and from different traditions that are not essentially concerned with education. It is the ideas of Hayek and Friedman, even of Adam Smith, that flowed into action in England in the 1980s, 
while the ideas of Hirst and Peters, enormously influential of the community of philosophers of education, bore little fruit in action. Somebody like David Young (now Lord Young), with a background in property and banking, was to have more influence on what actually went on in secondary schools than any contemporary professor of education; but the roots of what happened could be traced to earlier German and French ideas on vocational training. Ideas do have influence, but they cause no action unless those moved by them are in power.

Another practical rather than philosophical distinction to note is that communities of discourse operate in a rather isolated manner. They are never completely isolated, because the possibility of interchange always exists, but in circumstances of a given historical time such interchange sometimes simply does not take place. A good example of this is to be seen in the Britain of the 1970 s and early 1980s. Some of the ideas that influenced Conservative government policy in the later 1980s appeared largely under the auspices of The Institute of Economic Affairs. In a series of pamphlets and small books, a number of writers conducted a debate, within the parameters of radical free enterprise assumptions, about educational policy in a radically liberal society. ${ }^{1}$ At the same time within the community of philosophers of education, other debates were going on about the correct characterization of education, the nature of liberal education, perversions of such education through excessive authority and indoctrination, the rational justification of the curriculum, ethical considerations in education, and so on. ${ }^{2}$ It was almost as though the radically right-wing establishment and the liberal (in the old-fashioned sense) establishment were conducting their own debates but never actually engaging one another. Even worse, yet another debate was going on, more in conversation and speeches than in writing, about the shortcomings of British education in supplying trained manpower to stem our failing competitiveness in world trade. This was to be quickly influential in practice and only slowly and belatedly did philosophers of education engage in this debate - too late, at least in the short run, to prevent the wholesale characterization of education in highly instrumental and vocational terms. $^{3}$

In any attempt to influence educational decisions, (and presumably that is what we are all trying to do) there is always a twofold task: getting the arguments and prescriptions clear and well warranted, and giving the arguments salience by getting them shared by those people holding, or likely to hold, positions of educational and political power. British philosophers of education have, on the whole, been fairly good at the first of these necessities during the 1970 s and 1980s, but they have been remarkably unsuccessful at the second. Some day, there will be an interesting task for an historian to chart and analyse all of this. The truth of my claim can easily be seen, however, in any comparison between the debates engaging philosophers of education in these two decades and the level of writing (for it cannot be called debate) in the flood of documents, especially on the curriculum flowing from the Department of Education and Science in the same period. ${ }^{4}$ The writings of the philosophers hardly ever seemed to be taken up by the government writers, and, even where they were used, they were divested of their argued backing and used as authoritative utterances in the spirit of the government writers themselves.

It is not easy to allocate blame for the state of affairs in which these two discourses of education failed to engage. One might say that responsible agents 
in the politics of education ought to make themselves familiar with the theoretical debates in the area for which they are responsible. But for over a decade now, we have had a government in Britain which sees those professionally engaged in education (as in medicine, law, and other professions) as vested interests only concerned to defend practices which need radical change, and, therefore, not to be trusted in what they say or write. This, plus the fact that most philosophers of education had their bases in teacher-training institutions which kept them far too busy to engage in much politicking, is as far as I can go to provide possible explanation. The failure of politicians to become philosophers, or philosophers to become politicians, is as pronounced as when Plato went to Syracuse.

So there are marked and tragic gaps between the languages of power and those in theory. This is not the familiar and well-worked gap between theory and practice, though it is often talked about like this. In fact, there are countless examples of the interpenetration of theory and practice, sometimes for good and sometimes not. But this all takes place usually on a smaller scale than the gross impact of national policy-making. Even here though, strange things happen to educational discourse, and I now turn to discuss some of these largely, but not exclusively, in relation to what I shall call the metamorphosis of concepts -- a common phenomena in educational discourse.

Within the constraints determined by the exercise of power in the way I have just been discussing, teachers are somewhat more directly influenced by ideas and theoretical reflection. They are influenced to some extent by what they have heard in their training establishments, by what they hear on in-service courses and -- though to a considerably lesser extent -- by what they read. They are, of course, even more influenced by the advice, injunctions, admonitions and downright commands emanating from sources of power. Where the utterances from these sources are considerable and frequent, as in Britain in the 1980s, and because of the limits of time and energy available, teachers become less and less speculative and more and more pragmatic. In other words, their questions are more likely to be of the kind: "What is it that I am required to do?" or "How can I successfully do what is required of me?" and far less likely to be about the research and argument that might inform and enhance educational decisionmaking. The effects of this are multivarious, but two are germane to my present concerns: the pressure on time and energy urges towards oversimplification to the point of distorting ideas; and the pressure to conform to powerful requirements urges to a kind of latching-on to concepts, ideas, or theoretical prescriptions that appear to be conveniently related to the things teachers are being compelled to do anyway. To say that this is a salving of one's professional conscience is probably to go too far -- but it is something like this. I come to examples in some detail in a moment. Before that, however, it must be noted that a professionally disastrous consequence of all this is a growing disregard for the findings of research or argument, and a determination to persist with an idea or prescription even when research showing its falsity is readily available, and when arguments showing the ideas to be ill-founded have been well rehearsed in earlier literature.

A good example of some of the things I have just mentioned is what has happened to the idea of process in education. One of the reactions against curriculum planning based on behaviourally observable outcomes -- behavioural 
objectives -- was Lawrence Stenhouse's espousal of the concept of process. The way in which this idea filtered through to many teachers and local education authority advisers and inspectors was that we should not worry too much about the acquisition of 'facts' or 'knowledge' but concem ourselves much more with pupils' initiation into the processes of learning and discovery or, to put it another and more commonly expressed way, the acquisition of the skills of learning, problem-solving, and communication which were held to be broadly generalizable across the curriculum. This was not what Stenhouse had said, as I shall try to show, but the oversimplification, not to say falsification, was conveniently agreeable in many ways because of its compatibility with what teachers were being told to do.

Teachers were being told early in the 1980s that they must do more to produce young people who were capable and adaptable, to be ready to enter a culture which "emphasizes the day-to-day management of affairs, the formulation and solution of problems and the design, manufacture and marketing of goods and services" and not to go on producing people who were "able to understand but not to act." 5 Talk of skills and processes appeared to fit in with this kind of pressure. There was also a growing realization that rapid technological change would make very specific vocational preparation in schools difficult, in spite of urgings in this direction. The promise of generalizable skills are like those of problem-solving offered as one of the processes of learning looked like what was required by adaptability. There was, thus, an absorption of ideas of process which provided an apparent theoretical backing for ideas coming essentially from agencies of political and economic power.

That the theoretical ideas were bowdlerised, and were falsified seems evident when are reviewed what the theoretical advocates of a process curriculum had said. If one looks at the development of the idea of process in educational terms in the work of Bruner and Stenhouse for example, ${ }^{6}$ one seems a much more subtle idea of what process in education is supposed to be. A complex amalgam of logical and conceptual structures related together by specific intellectual procedures, and sometimes by physical procedures as well, is held to constitute a discipline of inquiry which serves our understanding. Such a discipline cannot be entered into to the point of being able to use it to serve one's own understanding by any mere memorizing of the 'facts' which are but the outcome of the inquiry used by others. The learner has to be authentically engaged in the procedures themselves, and to structure his or her own mind in the particular logical and conceptual structures of the discipline. A teacher, therefore, does not set out essentially to stock pupils' minds with particular bodies of 'facts', neither does the teacher set out solely to equip pupils with sets of behavioural skills. The teacher has the much more difficult job of initiating pupils into the whole network of thought and action constitutive of the discipline. Some of this has to do with appropriate attitudes and disposition. Some of it has to do with the sharing of values and certain conceptions of worthwhileness. A lot of it has to do with becoming aware of, practising and making one's own the appropriate procedures of the discipline. Some of it involves gaining familiarity with certain kinds of intellectual content. But even this is largely to do with coming to see why such content is appropriate, how concepts can be tested for appropriateness and propositions for coherence and truth, and why certain beliefs are justifiable and others not. This is what a 
concern for process looks like in the work of Bruner and Stenhouse. This is the idea that was to make Stenhouse sceptical of the value of planning curricula either on the basis of content acquisition or on the basis of some over-simplified skills analysis.

Process thus understood is in accord with the general liberal prescriptions of the philosophers of education of the $1970 \mathrm{~s}$ and early $1980 \mathrm{~s}^{7}$ since rational autonomy is obviously enhanced to the extent that a pupil makes the procedures, dispositions, attitudes, and values of disciplined inquiry genuinely his or her own. It is a fascinating example of what I am trying to describe that, apparently without anyone's deliberate intent, such a concept should become transmogrified into the oversimplified and largely behaviouristic form that accords much more with the instrumental and vocational view of education urged, indeed compelled, by the economic and political power sources.

Worthy of note, too, is that, when this metamorphosis occurs, there is a carry-over of the original emotive or normative meaning of the word despite the significant change in connotation. In other words, a concern for 'process' still has a liberal and progressive ring even when it has come to refer mainly to the inculcation of performance skills. Many teachers compare 'process' favourably with 'product' whilst in all their classroom activities seeking to produce products in terms of observable performance skills!

This, then, is what I am describing: a picture of a range of educational languages or discourses, some barely engaging with others at all, others appearing to engage but only with gross over-simplification and distortion, while only sometimes and perhaps rarely is there the common ground of accepted concepts and shared tests of truth held to be the prerequisite of meaningful discussion. If this is correct, then it is hardly surprising that philosophers of education find it so difficult to convey their ideas to others, and even more difficult to make them effective in changing things.

One can find enough other examples of the distortion and oversimplification of concepts as they pass from one community of discourse to another to be convinced of the reality of this phenomenon, and I shall discuss at least one other example further on. Nevertheless, in the case of the concept of process, it is possible to argue that the shift from the intended meaning was facilitated in part by the use of the word 'process' in the first place by writers like Stenhouse and Bruner to convey the idea they had in mind. Michael Oakeshott, particularly, criticizes any attempt to understand human action in terms of psychological or sociological processes. Human beings engage in trying to understand themselves and the world they inhabit, he says, and this, of course is the position of pupils:

... (they) are neither biological organisms identified in terms of their genetic characters, nor 'psychological egos', but reflective intelligences whose actions and utterances are choices to do or say this rather than that in relation to imagined and wished-for outcomes. And the relationships between them to be investigated are recognized to be themselves expressions of intelligence which may be enjoyed only by their having been learned and understood and in virtue of an acknowledgement of the authority of their conditions or of a recognition of their utility. The subject of inquiry in this enterprise of intellectual understanding is actions and utterances in respect of being subscriptions to procedures or 'practices' comprised of rules and rule-like con- 
siderations whose postulates are beliefs. It is a science of intelligent procedures, not processes. ${ }^{8}$

Oakeshott sees one of the many embodiments of procedures in 'practices' which human beings engage in as education itself:

Indeed, agents as historic persons composed of acquired beliefs, understandings, sentiments, imaginings, aptitudes, arts, skills, etc., and capable of self-disclosure in actions, themselves emerge in a transaction between the generations called education, in which newcomers to a local human scene are initiated into its 'mysteries'; that is, into practices which human beings have invented for themselves. And like every other transaction inter homines, this engagement to educate is itself utterances, actions and responses governed by a practice in which a relationship, distinguished from all others, is articulated: the relationship of teachers and leamers. And what is leamed in this transaction is languages of self-disclosure and self- enactment; not what to do or say, but the arts of agency. ${ }^{9}$

Oakeshott emphasizes the fact that procedures are always constituted of human understandings; that is to say, they are only to be fully participated in by sharing the understandings which they embody. Processes, on the other hand, do not necessarily arise from nor embody human understandings. We talk, for instance, of the process of decay, the process of photosynthesis, or the processes involved in reproduction. In the sense of this distinction, one could be instrumentally or vocationally educated by involvement in the physical, technological, or social worlds as part of a system of processes. Indeed, that is what many vocationally oriented courses and many life-skills courses involve: pupils are taught "what to do for say." On the arguments of Oakeshott and of many other liberal educators, this is to fail to liberally educate, to fail to get pupils properly to understand the world of human conduct in which they are placed. For this proper understanding and its consequential intellectual liberation, pupils need to be involved in the procedures and practices of persons which give sense not only to the actual goings on of people around them but to the artefacts that surround them also. Pupils have to acquire "the arts of agency." Such arts always comprise both doing and understanding, not so much as a blend of two separate things, but rather in the sense that neither the acts of agents nor the understanding of agents can have any separate meaning. Dichotomies like "theory and practice," "the practical and the academic," "being capable and being intellectual," "process and product," and "knowledge and skills" are seen to be abstract deceptions under this kind of analysis.

'Procedure', then, might have been a better term for Stenhouse and Bruner to have used than 'process'. Although one could never be sure that the full meaning would have penetrated into areas where it could be effective, for reasons previously discussed, at least the idea that procedures are human constructions and embody human understandings which need themselves to be shared and understood is nearer the surface, and to that extent is itself more likely to be itself understood and implemented. It is in this strategic sense that the concepts we use and the terms we use to express them do matter. I have argued elsewhere, in a quite different context of educational argument, that the well-known Humanities Curriculum Project which Lawrence Stenhouse directed, might well have had an easier ride if the term 'impartial' had been used to label the teacher strategy for handling controversial issues in the classroom, 
rather than the term 'neutral' which caused so much confusion. ${ }^{10}$ Other examples could no doubt be found.

The term 'skill' has already cropped up several times in the earlier paragraphs of this paper, largely in discussing the change of the idea of process into ideas of generalizable performance skills. One would need a book to examine all that has happened to this term and the range of concepts it picks out in the educational world in recent years. Because it is an important example of the general arguments of this paper, however, it is worth looking at this from at least some of the many points of view that could be considered.

First, consider the ways in which 'skill' has come to have such a favourable emotive or normative meaning. Britain is widely held to have a skills shortage. That means, of course, that we are short of certain kinds of manpower skills. Nevertheless, this is commonly referred to without the qualification, even in the more serious newspapers, and this is significant. The move from seeing that we need more printed circuit designers, petroleum chemists or tool-makers -- a problem with highly specific solutions -- is changed into a belief that we are short of skills in some general way. This seems to call for general solutions and the call for such solutions is often directed at schools of general education. Thus, any attempt to equip pupils with more skills is seen as a good thing. Such arguments are, of course, never laid out syllogistically. It is rather that a pervading ideological ambience is created in which almost anything referred to as a skill is unreservedly good. The notion of skills also has mental and affective associations with the practical and the useful, despite the reasonably obvious fact that a person can be skilful at intellectual things like mathematical analysis or philosophical argument, or at things that are trivial, immoral, or criminal, like ludo, fraud, or safebreaking. Then again, skills are widely held to be observable and measurable. English teachers are being pressed harder and harder into accountability. Because observable performances can be measured and displayed, the skills-based curriculum can be an accountable curriculum.

So once again, we see a notion being absorbed by the teaching community because of its accord with what teachers were being forced to do anyway. This example, however, differs from the process example in a number of ways. The most important of these differences is that it would be very difficult to find a direct theoretical advocacy of the skills-based curriculum of the kind that can be found in the advocacy of the process curriculum in Bruner and Stenhouse. The main drive seems to have come in a downward seepage into schools from the work of the Manpower Services Commission and the Further Education Curriculum Development and Review Unit, agencies set up specifically to develop vocational skills training in young school leavers and young adults. Analysis of jobs into constituent skills was a feature of the work of these agencies, offering an apparently, though often specious, scientific basis for training. ${ }^{11}$

Another difference is that use of the skill-based curriculum idea in schools ran into some predictable difficulties. To be useful where the future vocational and educational careers of pupils were unknown, acquired skills needed to be generalizable. It also proved difficult to analyse all school subjects into components that could properly be described as skills. The result was twofold: the term 'skill' became extremely wide in its denotation, indicating now aspects of personality previously spoken of as imagining, understanding, knowledge, em- 
pathising, relating, communicating, and so on. It, thus, became possible for teachers to see many of these 'skills' as indeed generalizable: if communication is a skill, then clearly it is a generalizable skill. Alongside this went a naive acceptance that many other skills, especially the newly discovered social and life skills, were generalizable in spite of all the evidence to the contrary. In other words, the arguments and evidence that were available about skills and transfer of training were not in this case incorporated, even in simplified or bowdlerised form; rather, they were simply ignored. They could not be incorporated because attention to what the argument and evidence said would have made a skillsbased curriculum impossible in any full sense.

The theoretical considerations were and, of course, still are of two forms. Firstly, there are conceptual considerations as to what might properly be referred to as a skill and the consequences of alterations in connotation or denotation of the term. Secondly, there are empirical investigations going back a considerable time concerning the possibilities and limitations of generalizable skills -- investigations into what the psychologists normally refer to as transfer of training. It is still worth looking at both of these considerations.

In 1966, Peters was able to write:

Skills, for instance, do not have a wide-ranging cognitive content. There is very little to know about riding bicycles, swimming, or golf. It is largely a matter of 'knowing how' rather than 'knowing that', of knack rather than understanding. ${ }^{12}$

And although a few might have had niggles at this, it no doubt matched a common use of the word at that time. By 1981, however, we find The Schools Council, a government supported agency for curriculum development, referring to the following as skills:

initial reading and number skills, ability to work alone, ability to work with others, a knowledge of political processes, ability to interpret scientific data, ability to make judgments on environmental matters, verbal skills as vehicles for thought, feeling and emotion. ${ }^{13}$

Vastly longer lists could be found in many other documents of the time, especially in some of the curriculum analyses carried out in schools in order to make curricula skills-based. As a critic at the time put it:

It begins to look as if we have only to dub any desirable capacity or area of experience a "skill' in order to suggest it can be easily identified and acquired. ${ }^{14}$

Not only identified and acquired, of course, but observed, measured and used to order and structure a largely instrumental curriculum of the kind required by those in power.

An interesting attempt to mark the limits of application of the term 'skill' was made in a publication of The Council for Science and Society concerned with new technology, employment, and skill. Although they recognized that skill required active practice, they did not agree with Peters' description of skill as a knack. The practice, according to these writers, is always more than simple repetition because it involves control, variation, and knowledge in the service of some end. Skill was, thus, more cognitively laden than Peters seemed to be saying. Whilst this appeared to open the way for some proper widening of the use of the term, a sharper cut-off point in a different direction was also sug- 
gested. The idea here was that the term 'skill' could never properly be used about activities intended to influence people without the implication that something improperly manipulative was going on. Thus, these writers were able to say:

On one side skill is marked off from more trivial accomplishments such as dexterity or 'knack'. On another it is distinguished from activities which are intended to affect people rather than things ... 'managerial skill' has a manipulative sound if it is applied to people..$^{15}$

These suggested limiting conditions have always seemed to me sensible ones according with the normal usage of the term and setting the kind of constraints which make the term useful, meaningful, and discriminable. They do not accord, however, with the widening use of the term in education to include a whole range of social, moral, interpersonal, and even aesthetic activities. These concerns for life, persons, and society are complex and only to be understood by highly cognitive involvement with interrelating concepts and bodies of propositions. Reduction of this area of human knowledge and conduct to lists of observable skills and performances is grossly to distort what it is to be involved in and try to understand the personal, social, and moral world.

Philosophers of education are often criticized for their concern with conceptual analysis, as though this concern is for something quite unrelated to the 'real' world, like a game or a crossword puzzle. But what people choose to call things and ideas is often an important indicator of what is going on in terms of power and social pressure, especially when the choice of terms involves considerable conceptual shift, as often seems to be the case in education.

The general application of what is taught in schools of general education is, perhaps, an aspect of curriculum theory that is not sufficiently considered. There is, however, a good deal of tacit awareness of its necessity. It is not surprising, therefore, that we find claims that the 'skills' that are taught in schools are generalizable. Some such claims are simple fantasy, aimed merely at enhancing the status of some activity in the curriculum. ${ }^{16}$ Others appear to embody more genuine beliefs -: though these are often the kind of strong beliefs that Quinton reminds us are not necessarily rational beliefs. ${ }^{17}$ Very few of these claims appear to have any backing of evidence or argument and, more strangely, at least some of the claimants appear to see no need for such evidence! ${ }^{18}$

Conceptually and logically, of course, if we make the connotation of a term narrower or vaguer, thereby widening its denotation to catch-all proportions, as I am claiming has happened to the term 'skill', then at least some of these 'skills' are likely to be genuinely generalizable. If reading, talking, and listening really are skills, then of course they are generalizable. That is to say, they are useful in a very wide range of circumstances. These are the most common examples given because of the assumed obviousness. What is often not noted is that even in the so-called communication skills much hangs on the user having some cognitive content to convey or to wish to receive. Whether the performances referred to as communication skills can really be abstracted from the total cognitive context is highly doubtful. This is, however, to re-enter the argument about the characterization of skills. What is usually at issue in a claim for the generalizability of a skill is empirical proof.

It is neither possible nor desirable here to do the kind of research review 
that is necessary to substantiate my claim that empirical research does not on the whole support the idea of generalizable skills. For anyone wishing to probe this a good start is to use the index of Sternberg's useful collection of papers in the Handbook of Human Intelligence. ${ }^{19}$ I will limit myself to quoting some remarks and notes by Resnick in a recent article specifically referring to claims about transferable problem-solving skills. These are frequently mentioned by teachers as the kinds of generalizable skills that can be cross-curricular and also have wide application beyond school. Resnick ${ }^{20}$ notes, however:

... some of the historical evidence that argues for caution and scepticism about the possibilities for effectively teaching general thinking and reasoning skills. First, cognitive research yields repeated demonstrations that specific knowledge plays a central role in reasoning, thinking, and learning of all kinds. General skills, such as analysing the problem into simpler problems or checking to see whether one has captured the main idea of a passage, may be simply impossible to apply if one does not have a store of knowledge about similar problems -- or know enough about the topic to be able to recognize its central ideas.

In other words, a curriculum cannot be reduced to skills, or analysed simply in terms of skills, because what will provide the generalizability is not the skills but the cognitive setting within which they operate. Even then the generalizability is likely to be limited as Resnick goes on to point out:

The second important reason to maintain some scepticism about the possibilities for directly teaching general skills for thinking and learning comes from a long history of research on transfer among school subject matters. It has proposed for decades that certain school subject matters would "discipline the mind" and therefore should be taught not so much for their own sake as for their value in facilitating other leaming. Latin was defended for many years in these terms; mathematics and logic are often so defended today. Most recently, learning to program computers has been proposed as a way to develop general problem-solving and reasoning abilities, yet this view, that we can expect strong transfer from learning in one area to acrossthe-board improvements, has never been well-supported empirically. (My emphasis.)

Even in the areas of adult training, from whence I have said these ideas have filtered down into schools, and where ideas of transfer strongly persist, the supporting evidence is scant and hardly positive. Resnick reports on recent programmes using de Bono's CoRT Thinking Program and the Productive Thinking Program, both aimed at equipping trainees with generalizable thinking and reasoning skills:

The Productive Thinking Program has been quite extensively evaluated over a number of years. There is evidence that students in the program become good at generating ideas and questions and show gains in the use of planning strategies in the kinds of problem situations on which training is given. However, we do not know if students actually apply these skills in practice. There has been far less attention given to evaluation of the CoRT program, other than observations of students during training and reports of teachers.... Despite many testimonials, we do not really know what kinds of effects these have on school leaming or success in practical problem-solving.

Here we have it again then: a practice and a community of discourse that one 
can only call prejudiced -- if to be prejudiced is to continue to believe and act where the beliefs are unjustified -- failing to engage with another community of discourse which would illuminate this lack of justification. I cannot really believe that this is due to some innate antipathy towards theory on the part of British teachers. It seems far more likely that the explanation lies in the power constraints within which such teachers now work and their efforts to maintain professional credibility and self-esteem within such constraints. That such a hypothesis is at least plausible is indicated by the examples I have given. For theory is engaged, even if distorted and oversimplified, where it appears to support what teachers are compelled to do anyway; but it is ignored in a strange, almost pathological, way when to acknowledge its existence and its truths would make it intolerable to continue practices, compelled by powerful decisionmakers, and shown by the theory to be unjustifiable or at least dubious. How else do we save the phenomena?

Two final points must suffice. Firstly, it is, of course, true that some teachers do transcend these ideologies and power-traps. The skilful and determined maintain their autonomy of thought, if not entirely their autonomy of professional action, and seek the truth where the evidence and arguments lead. One meets many of these teachers on in-service courses, and heart-warming and faith-restoring such contact is. But one is bound to say that such teachers do not seem to constitute a majority. Secondly, if there is any truth at all in what I have been saying, what then can philosophers of education -- and, indeed, other workers in the theory of education -- do? The answer, I believe, is that in their professional capacity they can only go on doing what they have always done: get the concepts clear and discriminable; get the arguments coherent, cogent, and valid; get the prescriptions rationally justifiable and show clearly those that are not. If they are to influence events, however, and not simply play these games with their students and amiably like-minded colleagues, then they will always have to do more. They will have to engage in politics -- though this might well be committees and working parties rather than what is usually thought of as party politics. They dare not eschew rhetorical engagement, uncomfortable alliances, or the boring rituals of getting to know those in positions of influence. To stand off from all this is to leave the game to others -- and that is largely what has happened. 


\section{Notes}

${ }^{1}$ See, for example, S.R. Dennison, Choice in Education (London: Institute for Economic Affairs, 1984); Alan Maynard, Experiment With Choice in Education (London: Institute for Economic Affairs, 1975); and Stuart Sexton, Our Schools: A Radical Policy (London: Institute for Economic Affairs, 1987). The bibliographies are also indicative of the whole school of thought.

${ }^{2}$ The works of Richard Peters and Paul Hirst are too well known to need listing. The discussion of liberal education is particularly taken up in Charles Bailey, Beyond the Present and the Particular: A Theory of Liberal Education (London: Routledge and Kegan Paul, 1984). (Henceforth BPP.)

${ }^{3}$ See $B P P$, Chapter 9.

${ }^{4}$ There are marked differences in emphasis between the strictly government (DES) papers and those produced by Her Majesty's Inspectors (HMI). The latter were on the whole more liberal and claimed to be independent of government control. Some always doubted this and the ways in which HMI have become increasingly constrained is really part of the story. But see, for example: DES: Education in Schools: A Consultative Document (London: HMSO, 1977), DES: A Framework for the School Curriculum (London: HMSO, 1980), HMI: $A$ View of the Curriculum (London: HMSO, 1980), DES: The School Curriculum (London: HMSO, 1981). Many documents emerged throughout the 1980s, culminating in DES: The National Curriculum: A Consultative Document 1987 and the implementation of the proposals therein in the Education Reform Act 1988.

5"Manifesto of Education for Capability," The Times Educational Supplement (London), 18 February, 1983, 13.

${ }^{6}$ For Laurence Stenhouse, see particularly his An Introduction to Curriculum Research and Development (London: Heinemann Educational, 1975). See also the convenient collection of extracts in Jean Rudduck and David Hopkins (Eds.), Research as a Basis for Teaching (London: Heinemann Educational, 1985). The Bruner works are, I believe, well known.

${ }^{7}$ Not only the educational philosophers in the Hirst and Peters school, but political philosophers, too. See, for example, the important chapter on liberal education in B. Ackerman, Social Justice in the Liberal State (New Haven: Yale University Press, 1980), Chapter 5.

${ }^{8}$ Michael Oakeshott, On Human Conduct (Oxford: Clarendon Press, 1975), 23-24. A collection of Oakeshott's writings on education has recently been published. See Timothy Fuller (Ed.), The Voice of Liberal Learning: Michael Oakeshott on Education (New Haven: Yale University Press, 1989). But this contains nothing from On Human Conduct, and the interested reader should read at least Part I of that work.

${ }^{9}$ Oakeshott, On Human Conduct, 59.

${ }^{10}$ See Charles Bailey, "Neutrality and rationality in teaching," in D. Bridges and P. Scrimshaw (Eds.), Values and Authority in Schools (London: Hodder and Stoughton, 1975), 121-135.

${ }^{11}$ The flavour can be seen in Further Education Curriculum Development and Review Unit: A Basis For Choice (London: HMSO, 1979) and FECDR: Vocational Preparation (London: HMSO, 1981). For teachers' incorporation of the idea of 'skill-ownership', see Chapter 12, "Teaching and Learning 
Methods," in R.G. Wallace (Ed.), Introducing Technical and Vocational Education (London: Macmillan Education, 1985). 159.

${ }^{12}$ R.S. Peters, Ethics and Education (London: Allen and Unwin, 1966),

${ }^{13}$ Schools Council Working Paper 70: The Practical Curriculum (London: Methuen Educational, 1981), 22-23.

${ }^{14}$ Ruth Jonathan, "The manpower service model of education," Cambridge Journal of Education, 13 (2), 1983.

${ }^{15}$ New Technology: Society, Employment and Skill (London: Council for Science and Society, 1981), 7-8.

${ }^{16}$ All accounts of the encountered views of teachers are bound to be anecdotal. I refer to claims I have heard, for example, that skills of mechanical or mathematical problem-solving can generalize to the solving of problems in personal relationships! I have learned that I can no longer use this, as I once did, as a reductio absurdum example. Even with the (I would have thought) obviously self-destructive example of 'friendship skills', some have told me that moving this from fanciful example to actual curriculum content would hold no fears for them!

${ }^{17}$ A. Quinton, The Nature of Things (London: Routledge and Kegan Paul, 1973), 144.

${ }^{18}$ Again the evidence has to be anecdotal, as follows: As chairman of a board of school governors interviewing for a deputy-headship, I listened to a candidate talking of the virtues of generalizable skills. On being asked if she had any evidence to support her claims, the candidate laughed and said she knew nothing of any evidence. This I thought bad enough; but I was even more surprised when a group of teachers with whom I was discussing professionalism contained some teachers who saw no reasons why this should have counted against the applicant!

${ }^{19}$ R.J. Sternberg (Ed.), Handbook of Human Intelligence (Cambridge: Cambridge University Press, 1982).

${ }^{20}$ Lauren Resnick, "Instruction and the cultivation of thinking," Noel Entwistle (Ed.), Handbook of Educational Ideas and Practices (London: Routledge, 1990), 694-708. 